\title{
Refractory tinea caused by Aspergillus niger
}

\author{
Mary Kathryn Mannix, ${ }_{1}^{1}$ Lisa Marlin, ${ }^{2}$ Ilene Rothman, ${ }^{2}$ Shamim Islam ${ }^{1}$
}

${ }^{1}$ Department of Pediatrics, University at Buffalo Jacobs School of Medicine and Biomedical Sciences, Buffalo, New York, USA

${ }^{2}$ Department of Pediatric Dermatology, John R Oishei Children's Hospital, Buffalo, New York, USA

\section{Correspondence to} Dr Mary Kathryn Mannix; mmannix@buffalo.edu

Accepted 6 June 2020

\section{DESCRIPTION}

A 4-year-old boy presented to the clinic with a persistent rash despite ongoing management for fungal dermatitis. His foster mother for the past year described the presence of a large, raised and scaly scalp lesion when he first came under her custody. Though he had previously been neglected, there was no known history of frequent infections, atopic disease or other significant medical issues. His prior treatment regimen had included topical antifungal medications, ketoconazole shampoo and a 14-week course of two times per day, high-dose $(20-25 \mathrm{mg} / \mathrm{kg} / \mathrm{day})$ oral griseofulvin, but he had only mild improvement initially. Most recently, the rash appeared to be worsening and spreading to his neck and torso.

On physical examination, several circular and irregular patches, with raised, erythematous borders and central hypopigmentation, were prominent on his scalp, neck, abdomen and back (figures 1 and 2); the lesions were all clinically consistent with typical tinea capitis and corporis. The rest of his examination was normal.

A skin scraping grew Aspergillus niger on Sabouraud agar (fungal culture). He had already been placed on terbinafine, but dermatitis only progressed during 2 weeks of this therapy. Based on superior clinical effectiveness against Aspergillus, he was switched to voriconazole by infectious diseases specialists. The patient initially showed a strong response, especially with improvement on his scalp and his body lesions becoming less erythematous and smaller. However, after the first few weeks of therapy, lapses from continuous voriconazole treatment led to a recrudescence of the tineaconsistent rash. He ultimately was felt to also have

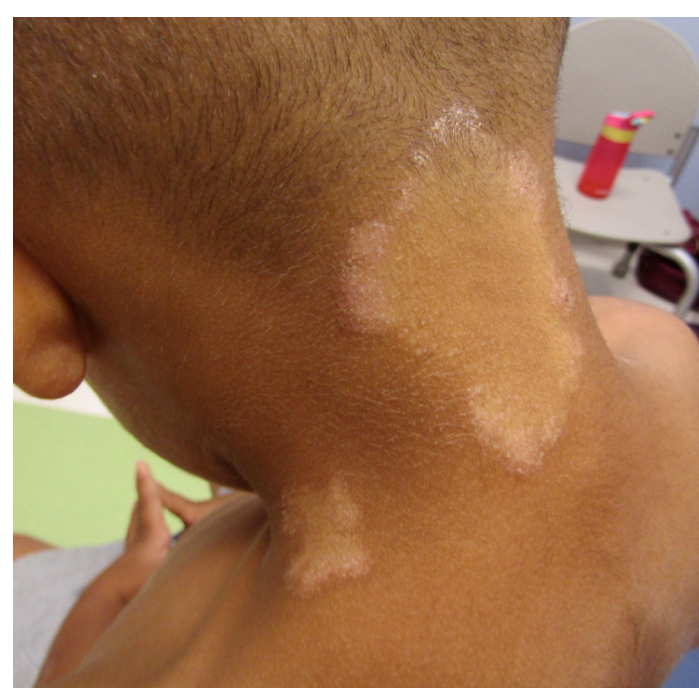

Figure 1 Patient's neck lesions.

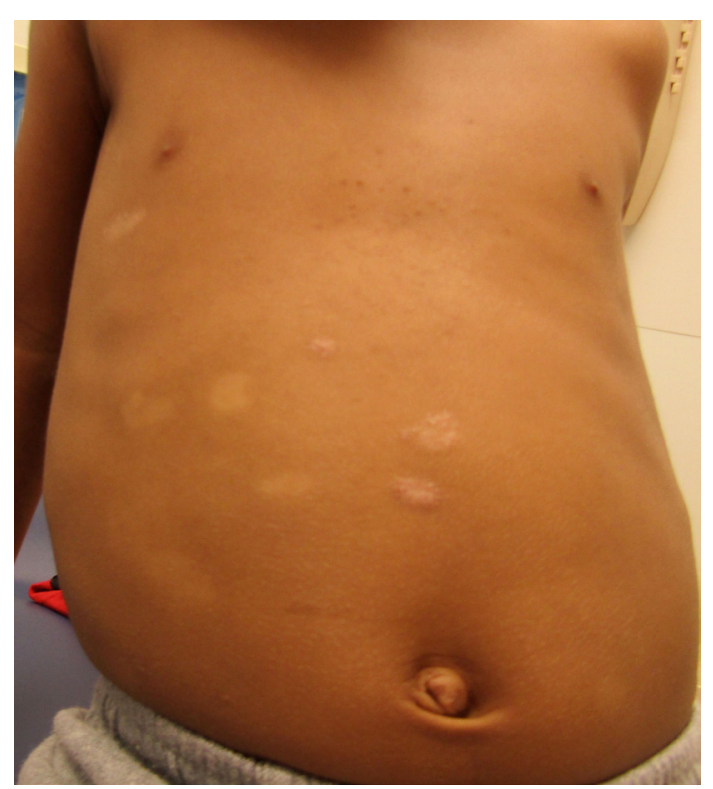

Figure 2 Patient's truncal lesions.

secondary immunologic dermatophytid (id) reaction lesions on his body, which responded to topical corticosteroids.

Recent international reports note changing aetiology of superficial mycoses, with the emergence of non-dermatophyte fungi, particularly Aspergillus species, causing tinea capitis and onychomycosis. ${ }^{12}$ One study in India found that $14.5 \%$ (9/62) of the superficial (skin/nails) fungal isolates were nondermatophyte moulds including Aspergillus spp. ${ }^{3}$ In a 2018 report from Ethiopia, 46\% (76/164) of the superficial fungal isolates were non-dermatophyte moulds with Aspergillus spp commonly isolated. ${ }^{4}$ Additionally, a 2019 case report from China described a kerion-type scalp mycosis caused by Aspergillus protuberus in a 5-year-old child, which responded to oral terbinafine treatment. ${ }^{5}$ A. niger underlying prolonged scalp tinea with alopecia, similar to our patient, has also been reported in two children in Brazil. ${ }^{2}$

Learning points

- There are increasing reports internationally of non-dermatophyte fungi, including Aspergillus, causing tinea capitis and onychomycosis.

- In cases of tinea capitis which respond poorly to conventional therapy such as griseofulvin, consider moulds as the potential aetiology, for which terbinafine and systemic azole antifungals are likely to be effective. 
Aspergillus species are a leading causative organism of nondermatophyte mould onychomycosis (NDMO). In a review of international studies from 1974 to 2017, over 50\% (23/42) included NDMO cases isolating Aspergillus. NDMO caused by Aspergillus spp responds well to systemic agents, and in vitro, itraconazole performs better than terbinafine. ${ }^{1}$ A Cochrane review found terbinafine to be more effective than griseofulvin for onychomycosis, and terbinafine combined with an azole was more effective than terbinafine alone, without any increase of adverse events. ${ }^{6}$ This case of Aspergillus underlying a superficial mycosis represents an unusual but potentially increasing presentation around the globe. In paediatric patients with tinea capitis who fail to respond to conventional therapy, non-dermatophyte fungal aetiologies and alternative systemic antifungals should be considered.

Contributors MKM and SI conceived the report, assessed the patient and drafted and finalised the report. IR and LM assessed the patient, took the pictures and selected the figures. SI and IR contributed to the revision of the final report.
Funding The authors have not declared a specific grant for this research from any funding agency in the public, commercial or not-for-profit sectors.

Competing interests None declared.

Patient consent for publication Parental/guardian consent obtained.

Provenance and peer review Not commissioned; externally peer reviewed.

\section{REFERENCES}

1 Bongomin F, Batac CR, Richardson MD, et al. A Review of Onychomycosis Due to Aspergillus Species. Mycopathologia 2018;183:485-93.

2 Chokoeva AA, Zisova L, Chorleva K, et al. Aspergillus niger - a possible new etiopathogenic agent in Tinea capitis? Presentation of two cases. Braz I Infect Dis 2016;20:303-7.

3 Hazarika D, Jahan N, Sharma A. Changing trend of superficial mycoses with increasing nondermatophyte mold infection: a clinicomycological study at a tertiary referral center in Assam. Indian J Dermatol 2019;64:261-5.

4 Bitew A. Dermatophytosis: prevalence of dermatophytes and Non-Dermatophyte fungi from patients attending Arsho advanced medical laboratory, Addis Ababa, Ethiopia. Dermatol Res Pract 2018;2018:1-6

5 Jia J, Chen M, Mo X, et al. The first case report of kerion-type scalp mycosis caused by Aspergillus protuberus. BMC Infect Dis 2019;19:506.

6 Kreijkamp-Kaspers S, Hawke K, Guo L, et al. Oral antifungal medication for toenail onychomycosis. Cochrane Database Syst Rev 2017;7:CD010031.

Copyright 2020 BMJ Publishing Group. All rights reserved. For permission to reuse any of this content visit

https://www.bmj.com/company/products-services/rights-and-licensing/permissions/

BMJ Case Report Fellows may re-use this article for personal use and teaching without any further permission.

Become a Fellow of BMJ Case Reports today and you can:

- Submit as many cases as you like

- Enjoy fast sympathetic peer review and rapid publication of accepted articles

- Access all the published articles

Re-use any of the published material for personal use and teaching without further permission

Customer Service

If you have any further queries about your subscription, please contact our customer services team on +44 (0) 2071111105 or via email at support@bmj.com.

Visit casereports.bmj.com for more articles like this and to become a Fellow 